\title{
Comparative Evaluation of Film Thickness and Net Setting Time of Fuji I with a New Glass Ionomer Cement
}

Fatemeh Raoufinejad ${ }^{1}$, Baharan Ranjbar Omidi ${ }^{2}$, Siavash Kamali ${ }^{3}$, Fahimeh Nouri ${ }^{4}$, Faranak Solgi $^{5}$

1. Assistant Professor, Department of Operative Dentistry, Faculty of Dentistry, Qazvin University of Medical Sciences, Qazvin, Iran. ORCID ID: 0000-0002-5270-3934

2. Assistant Professor, Department of Operative Dentistry, Faculty of Dentistry, Qazvin University of Medical Sciences, Qazvin, Iran. ORCID ID: 0000-0002-4138-8166

3. Student of Dentistry, Student Research Committee, Faculty of Dentistry, Qazvin University of Medical Sciences, Qazvin, Iran. ORCID ID: 0000-0001-9260-6904

4. Assistant Professor, Department of Operative Dentistry, Faculty of Dentistry, Qazvin University of Medical Sciences, Qazvin, Iran. ORCID ID: 0000-0003-2718-8288

5. Post-graduate Student of Operative Dentistry, Student Research Committee, Faculty of Dentistry, Qazvin University of Medical Sciences, Qazvin, Iran., (Corresponding Author), Tel: 028-3353064, E-mail: Faranaksolgi@gmail.com. ORCID ID:

0000-0002-0346-7437

\section{ABSTRACT}

Background and Aim: Glass Ionomer cements have been used widely due to their biocompatibility, fluoride release and the ability to decrease the incidence of marginal caries . Minimum film thickness, adequate net setting time $\&$ high compressive strength are the main characteristics of a luting cement in clinical dentistry. The purpose of this study is to compare the film thickness \& net setting time of Fuji I and a newly developed GIC.

Materials and Methods: 20 samples were prepared with P/L of 1.8:1 for Fuji I \& 0.72:0.4 for Iranian cement. For the determination of net setting time, $5 \times 8 \times 10 \mathrm{~mm}$ metal mold was prepared. Ninety seconds after mixing, carefully lower the indenter $0.1 \pm 1 \mathrm{~mm}$ diameter vertically on the surface of the cement. Repeating the indentations at $30 \mathrm{~s}$. Net Setting Time was recorded as the time elapsed between the end of mixing time and the time when the needle failed to make a complete circular indentation. For the determination of film thickness, two flat glass plates was used and the thickness of both were measured with micrometer device. Then applied a $0.1 \mathrm{ml}$ of the mixed cement at the center of the lower plate and applied $150 \mathrm{~N}$ force to the specimen via the top plate. Then measured the difference of the two plates thickness with and without the cement as the film thickness of the cement. The data were entered into SPSS21 software and Kolmogorov Smirnov and independent T-test were used to evaluate the data.

Results: Fuji I had shorter mean value of Net setting time and smaller film thickness than Iranian cement.This difference was statistically significant.

Conclusion: Fuji I seems a better clinical choice for the cementation of indirect restorations than Iranian cement.

Keywords: Net Setting Time, Film Thickness, Glass Ionomer Cement

Received: Mar 13, $2019 \quad$ Accepted: Oct 9, 2019

How to cite the article: Fatemeh Raoufinejad, Baharan Ranjbar Omidi, Siavash Kamali, Fahimeh Nouri, Faranak Solgi. Comparative Evaluation of Film Thickness and Net Setting Time of Fuji I with a New Glass Ionomer Cement. SJKU 2020;25(2):37-43.

Copyright (C 2018 the Author (s). Published by Kurdistan University of Medical Sciences. This is an open access article distributed under the terms of the Creative Commons Attribution-Non Commercial License 4.0 (CCBYNC), where it is permissible to download, share, remix, transform, and buildup the work provided it is properly cited. The work cannot be used commercially without permission from the journal 


\title{
ارزيابى مقايسهاى ضخامت لايهاى و زمان تنظيم خالص سمان كلاس آينومرفوجى يك با يك نمونه كَلاس آينومر جديد
}

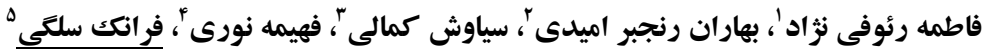

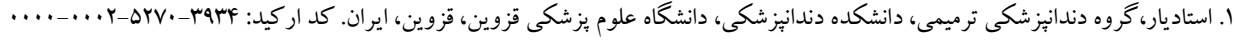

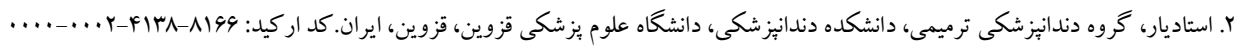

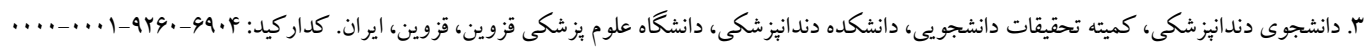

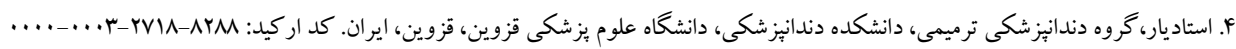

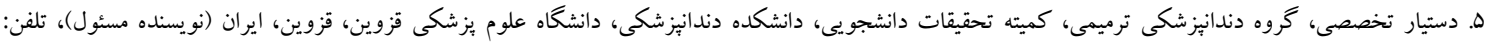

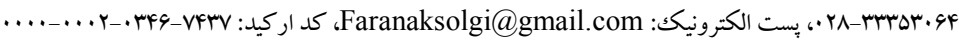

جـكيله

زمينه و هدف: سمانهاى گلاس آينومر امروزه بهدليل ساز گارى نسجى، آزادسازى فلورايد و كاهش بروز بوسيدگى لبهاى بسيار ير كاربرد هستند. سمانهاى دندانى بايد ويزّ گیىهاى اساسى از جمله حداقل ضخامت لايهاى، زمان تنظيم خالص ايـدهال و اسـتحكام فشارى بالا جهت استفاده كلينيكى دار باشند. هدف از اين مطالعه مقايسهى ضخامت لايـهاى و زمـان تنظيم خـالص سـمان خـلاس آينومر Fuji I با يكك سمان گلاس آينومر جديد است.

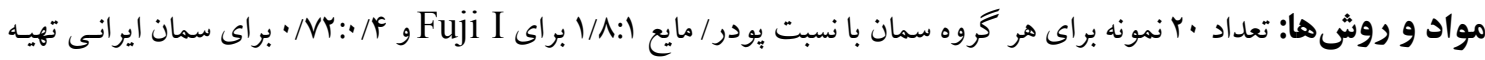

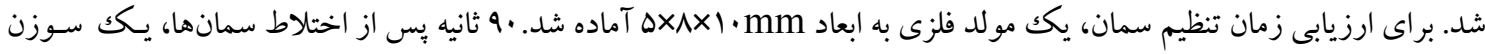

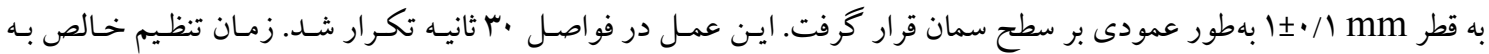
صورت مدت زمان بين اتمام اختلاط سمان تا زمانى كه سوزن نتو اند يكك فرورفتكى كامل دايره اى ايجاد كنـد محاسبه شـد. بـراى بررسى ضخامت لايهاى از دو صفحه شيشه اى اسـتفاده شــ. ضـخامت مجمـوع صفحات توسط دســاه ميكرومتـر محاسبه شـد.

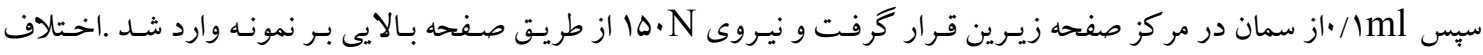
ضخامت دو صفحه باو بدون حضور سمان بين آنها بهعنوان ضخامت لايهاى سمان محاسبه شـد. دادههـا در نـرم افزار SPSS21 وارد و با استفاده از آزمونهاى Kolmogorov Smirnov وأt مستقل ارزيابى شدند. يافته ها: I Fuji ميانگين زمان تنظيمشدن كو تاهتر و ضخامت لايهاى كمترى در مقايسه با سمان ايرانى دارد و اين اختلاف از لحاظ آمارى معنى دارى است. نتيجه كيرى: Fuji I در مقايسه با سمان ايرانى انتخاب كلينيكى بهترى بر ای سمان كردن رستوريشن هاى غير مستقيم است . كلمات كليدى: زمان تنظيمشدن خالص، ضخامت لايهاى، سمان كلاس آينومر

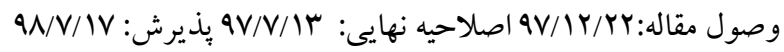


با هدف مقايسه ضخامت لايهاى و زمان تنظيمشـدن خـالص ميان سـمان گحلاس آينومر Fuji I و يـك نمونـه كـلاس آينومر جديد طراحى شدهاست.

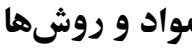

مطالعه حاضر يكك مطالعه تجربى -آزمايشگاهى است كه بِ از اخذ كد اخلاق IR.QUMS.REC.1397.093 در

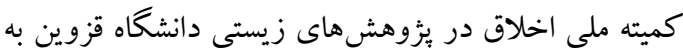

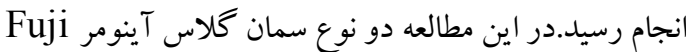
GC, Japan) I دندان، قزوين، ايران) مورد بررسى قرار گرفت. در اين مطالعه تعداد ·r نمونه در گروه گلاس آينومر فوجى يك فر

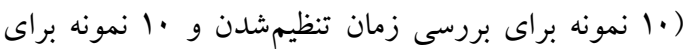

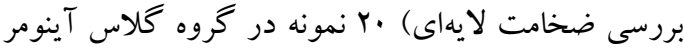
ايرانى (· انمونه براى بررسى زمان تنظيمشدن و •ا نمونه

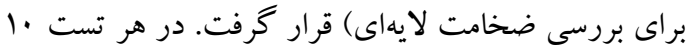
نمونه از هر كدام از ب نوع كلاس آينومر مورد مطالعه قرار كرفت؛ براى بررسى زمان تنظيمشدن خالص ( Net

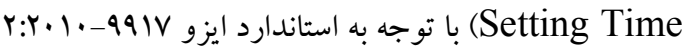
قالبى از جنس آلومينيوم در ابعاد

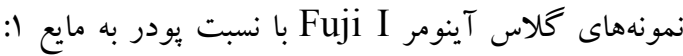
1/1 (مطابق دستور سازنده) بلهوسيله ترازوى ديجيتال Digital Balance(AND, Japan) كرم تعيين گرديده و به مدت ·r ثانيه مخلوط شد. سبس با استفاده از اسياتول دهانى به داخل قالبها منتقل شده و يس تهر از كذشت •9 ثانيه از زمان مخلوطشدن نمونهها، داخل

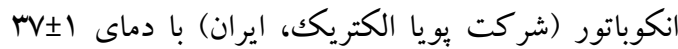

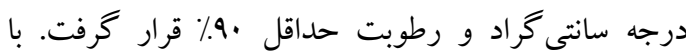
كذشت •ه ثانيه از زمان مخلو طشدن، سوزنى (Indenter)

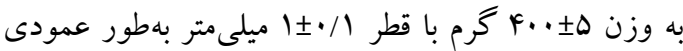
برروى نمونه سمان قرار كرفته و به مدت هـ ثانيه در اين

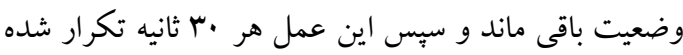

مقدمه

سمانهاى دندانى به طور گستردهاى در دندانيز شكى استفاده شــده و كاربردهــاى كلينيكـى متفــاوتى دارنـــ. سـمانهــا مى تو انند بهعنوان مو اد بيس، ترميم موقتى و سمان جسباننده عمل نمايند. همجنين انواع مختلفى از سمانها در درمانهاى ارتو دنسى و درمـان ريشـه نيـز بـهـ كـار گرفتـه مسى شـوند (1). كلاس آينومرها مواد حاوى مـاتريكسهـاى يليمرى هستـند

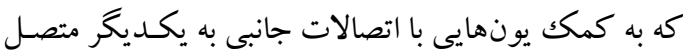

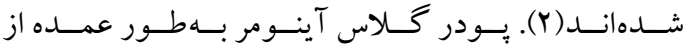
فلورو آلومينوسيليكات كلسيم تشكيل شدهاست كه فلورايـــ

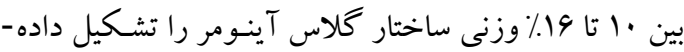

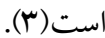

كلاس آينومرها بهعنوان خسباندن رو كش، مـاده ترميمى و

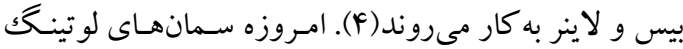
بهور گسترده براى جسباندن رستوريشنها و پِت و كورها

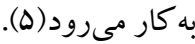
براى كار كرد كلينيكى قابل قبـول، سـمانهـاى دنـدانى بايـــ

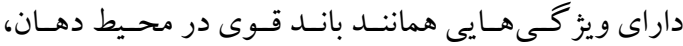
استحكام بالا تحت كشش، زمان تنظيم مناسب و ضـخامت فئ

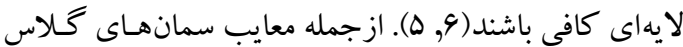
آينومر حساسيت به رطوبت، خشونت سطحى و سايش زياد

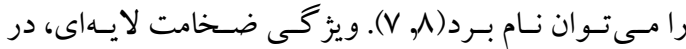
انتخاب يكك سمان مناسـب نقش بسيار مهمى دارد. جهـت نشست كامل يكك بِروتز در حين سمانتمودن بـا سـمانهـاى لوتينگك، لازم است كه سمان فلوى مناسبى داشته باشد تـا بـا حداقل ضخامت لايهاى در محل قرار گيرد. ضخامت لايهاى مناسب، سـبب كاهش عـدم تطابق لبهاى و متعاقباً كاهش بيمارىهاى بريودنتال و كاهش حلاليت سمان مىشود (9).

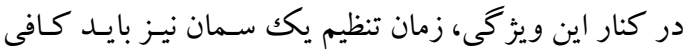

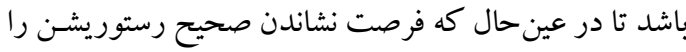

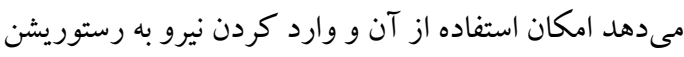
در حداقل زمان ممكن را فراهم نمايد؛ بنابراين، ايـن مطالهـه 
كرفته شد. نمونههاى تهيه شده از كَلاس آينومر ايرانى نيز با

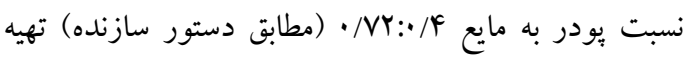
كرديده و مراحل بالاعيناً تكرار شد و نتايج ثبت گرديد. بهنظور تحليل دادهها از نرمافزار آمارى SPSS21 استفاده شد. براى بررسى نرمالبودن توزيع دادهها از آزمون kolmogorov smirnov مستقل براى بررسى رابطه متغيرهاى كمى و كيفى دوحالته استفاده شد. در اين مطالعه سطح معنىدارى (p-value) كمتر از ه.٪ در نظر كرفته شد.

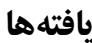
نتايج حاصل از جدول ا به شرح زير گزارش شد: با استفاده از آزمون t و مقدار p كه بيشتر از هـ/• بهدست آمد نتيجه مى گيريم بين زمان تنظيمشدن خالص اين دو سمان اختلاف معنىدار وجود دارد. (مقدار p را با عدد ه•/ مقايسه مى كنيم اخر عدد بهدست آمده از هـ/. كوجككتر بود اختلاف بين گروهها معنىدار و در غير اين

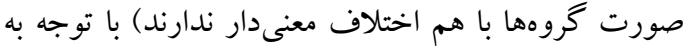
مقادير ميانخين جدول فوق مشاهده مىشود زمان تنظيمشدن در كلاس آينومر Fuji I كمتر از گلاس آينومر ايرانى

نتايج بهدست آمده از جدول r در مورد شاخص ضخامت لايه اى نيز به شرح زير گزارش شد: با استفاده از آزمون t و مقدار p كه بيشتر از هـ/• بهدست

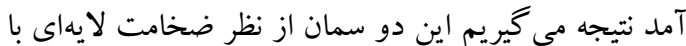
هم اختلاف معنىدار دارند. با توجه به مقادير ميانگين در جدول فوق مشاهده مى شود ميزان ضخامت لايهاى در سمان كمتر از كلاس آينومر ايرانى است. Fuji I
تا زمانى كه اثر نفوذ دايرهاى شكل انتهاى سوزن برروى كلاس آينومر قابل مشاهده نباشد و در نهايت از انتهاى زمان مخلوط كردن سمان تا زمانى كه سوزن اثر دايرهاى كامل بر روى گلاس آينومر ايجاد نكند بهعنوان زمان دقيق تنظيم شدن ثبت شد. نمونهاى تهيه شده از كَلاس آينومر ايرانى

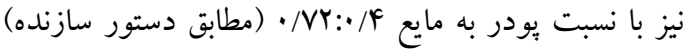

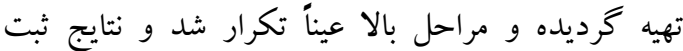
كرديد. براى بررسى ضخامت لايهاى سمانها با توجه به استاندارد

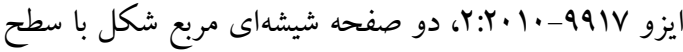

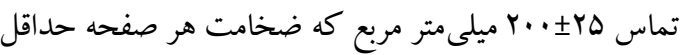
ه ميلىمتر بود تهيه شد. دو صفحه شيشهاى روى هم قرار

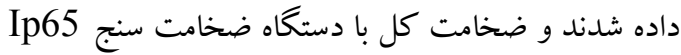
Water Proof Digital Calipers(Guanglu,China) اندازهيرى شد. ستس صفحه شيشهاى اول را برداشته و مقدار // ميلىليتر از سمان گلاس آينومر Fuji I با نسبت

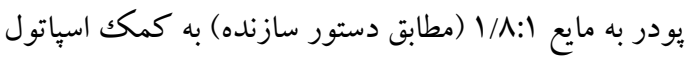
دهانى روى سطح شيشهاى گرفت. سيس شيشه دوم بر روى

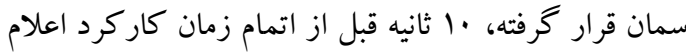
شده توسط كارخانه سازنده نيرويى به اندازه بـ •ها نيوتن

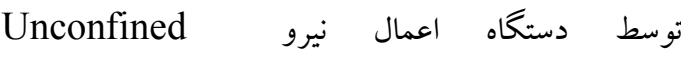
Compression(Wykeham,France) بر مركز صفحه شيشهاى وارد شد. بعد از كذشت .1 دقيقه از زمان واردشدن نيرو، مجموعه را از زير دستكاه خارج

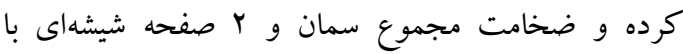

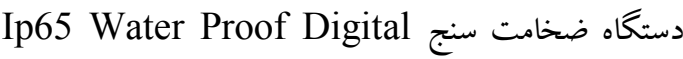
و Calipers(Guanglu,China) اختلاف اين دو عدد بهعنوان ضخامت لايهاى سمان در نظر 
جدول 1. تعيين و مقايسه زمان تنظيمشدن دو نوع سمان كلاس آينومر GC, Japan) Fuji I) با نسبت 1/1/1) و نمونهى

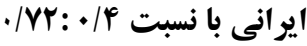

\begin{tabular}{|c|c|c|c|}
\hline P-Value & انحراف معيار & ميانكين (دقيقه) & سمان \\
\hline \multirow{2}{*}{$\cdot / \cdot$} & .1 .99 & $F / r q$ & Fuji I Fلاس آينومر \\
\hline & $\cdot / 1 \cdot V$ & $q / Y \Delta$ & كلاس آينومرايرانى \\
\hline
\end{tabular}

جدول r. تعيين و مقايسه ضخامت لايهاى دو نوع سمان كلاس آينومر GC, Japan) Fuji I با نسبت ا: A/ ا و نمونهى

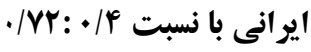

\begin{tabular}{|c|c|c|c|}
\hline P-Value & انحر اف معيار & ميانكين (ميكرومتر ) & سمان \\
\hline & $r / 1$ & $r \mid / \Delta$ & Fuji I Fلاس آينومر \\
\hline$\cdot / \cdot$ & $1 F / V$ & $99 / 4$ & كملاس آينومر ايرانى \\
\hline
\end{tabular}

از جمله مطالعهى White و همكارش (199r/ه) ميكرون)(rا)، مطالعهى Johnson و همكاران (1911)

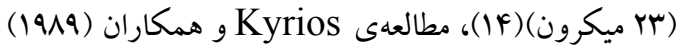

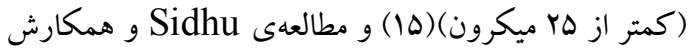

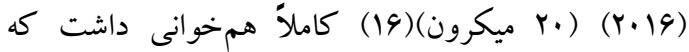
نشاندهندهى روش اجراى صحيح در مطالعهى بيشروست.

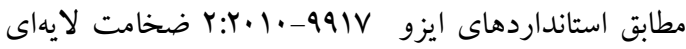
ايدهآل براى يكك سمان لوتينك بايد كمتر از ها ميكرون التهان

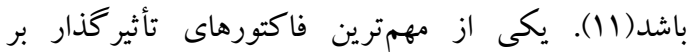
ضخامت لايهاى اندازهى متوسط سايز ذرات يودر كالاس و

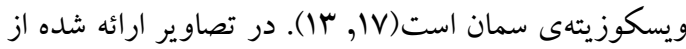
ميكروسكوٍ الكترونى مشاهده شد كه سايز ذرات يودر

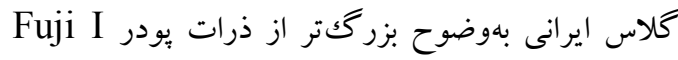
است به كونهاى كه متوسط سايز در سمان Fuji I در حدود r ميكرون است در حالى كه اين اندازه در سمان ايرانى در
امروزه دندانيزشكان با طيف وسيعى از سمانها روبهرو هستند كه هر كدام از آنها معايب و مزايايى دارند. در حال حاضر هيج سمان لوتينكى موجود نيست كه در تمام شرايط هرا كلينيكى عملكرد ايدهآلى داشته باشد (1). نتايج مطالعهى حاضر در بررسى متغير ضخامت لايهاى نشان

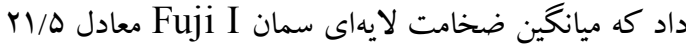
ميكرون و سمان ايرانى معادل 99/4 ميكرون بود و در نتيجه سمان ايرانى برخلاف سمان Fuji I نتوانست به استاندارد

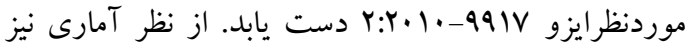
اختلاف معنىدارى بين اين دو گروه مشاهده شد(1). دادههاى حاصل از اين بررسى همجنين نشان داد كه ضخامت لايهاى سمان Fuji I در محدودهاى قرار دارد كه باى مقائ ro اطلاعات ارائه شده توسط كارخانه سازنده (كمتر از ميكرون)(Y (I) و دادههاى حاصل از مطالعات ساير محققين 
خالص ايدهآل براى يكك سمان لوتينك بايد حداقل 1/ه دقيقه و حداكثر 1 دقيقه باشد(1). يكى از عوامل تأثير كذار بر زمان تنظيمشدن خالص سمانها سايز ذرات بودر گلاس است؛ بهنحوى كه ذرات با سايز كوجکكتر، زمان تنظيمشدن سمان را كاهش مىدهند(ب/) و از آنجا كه سايز ذرات كلاس ايرانى بزرگكتر است اين موضوع نيز مىتواند تأثير گذارى در بالاتربودن زمان تنظيمشدن خالص سمان كلاس آينومر ايرانى در مقايسه با Fuji I باشد. همجِنين فاكتور مؤثر ديخر بر زمان تنظيمشدن سمان، غلظت التران تارتاريكك اسيد موجود در مايع سمان است. با توجه بهاينكه دمه دمان

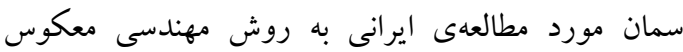
ساخته شده و طبق اطلاعات سازنده ميزان تارتاريكك اسيد

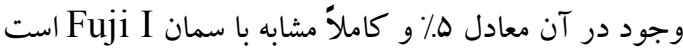

$$
\text { و اثر اين فاكتور بر زمان تنظيمشدن رد مى كردد. }
$$

\section{نتيجه كيرى}

نتايج اين مطالعه نشان داد كه گلاس آينومر Fuji I تنتخاب كلينيكى بهترى نسبت به كاس آينومر ايرانى است و سـمان

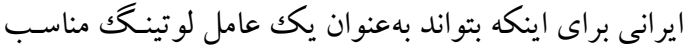

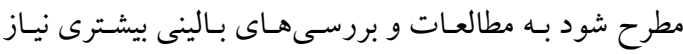

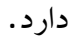

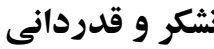

با تشكر از كار كنان محترم آزمايشكاه دانشكده بهداشـت دانشـكاه علـوم يزشـكى قـزوين كـه در ايسن تحقيـق مـا را

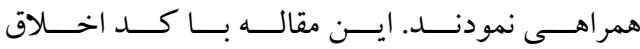
IR.QUMS.REC.1397.093 در كميته ملى اخلاق

$$
\text { در يزوهش هاى زيستى مصوب گرديد. }
$$

حدود ·. ميكرون است. اين موضوع مىتواند ضخامت لايهاى بالاتر سمان ايرانى را در مقايسه با سمان Fuji I

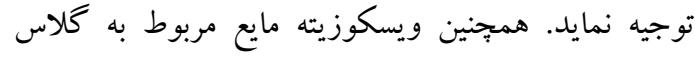

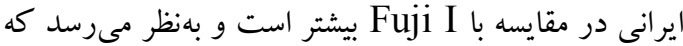
اين عامل نيز مىتواند در افزايش ضخامت لايهاى سمان ايرانى تأثير گذار باشد(1), rا). اين ويسكوزيته بالاتر به عeflux precipitation علت عدم استفاده از روش الترائ polymerization (RPP) سمان ايرانى است. در سيسم RPP بهجاى روش تقطير ساده از روش تقطير باز گشتى استفاده شده كه سبب مى إسود در حين تهيه مايع، آب در سيستم حفظ شود و در نهايت

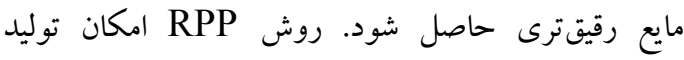
مونومرهاى ميكرو يا نانو از طريق كنترل دقيق سايز و توزيع روديع يكنواخت تر ذرات را فراهم مى كند (19). بررسىهاى مطالعه حاضر در مورد شاخص زمان تنظيمشدن خالص نشان داد كه ميانخين زمان تنظيمشدن خالص براى سمان Fuji I در حدود

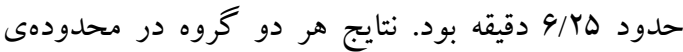

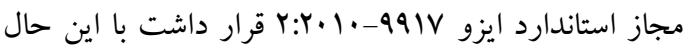
از نظر آمارى تفاوت معنىدارى بين دو گروه مشاهده شد(·r, 11) مطابق اطلاعات سازنده سمان Fuji I) زمان تنظيمشدن اين سمان در حدود هـ دقيقه است(rا, •1) كه اين زمان تنظيمشدن با نتايج حاصل از مطالعات Johnson و همكاران (19MM) (9/1 دقيقه)(IF)، Fleming

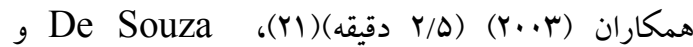

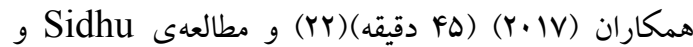

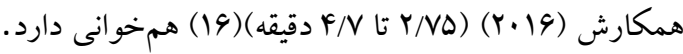

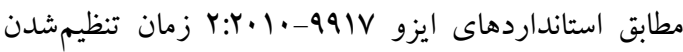

منابع

1. MCCABE JF, WALLS, Angus WG. Appl dent mat. John Wiley \& Sons, 2013.

2. Powers J, Sakaguchi R. Impression materials. Craig's restorative dental materials. Elsevier Mosby. 2006;294:95. 
3. WILSON AD, Chem C, MCLEAN J. W. Glass-ionomer cement. Chicago: Quintessence Pub. Co. 1988.

4. Mortier E, Gerdolle DA, Jacquot B, Panighi MM. Importance of water sorption and solubility studies for couple bonding agent-resin-based filling material. Oper Dent. 2004;29(6):669-76.

5. Meyer JM, Cattani-Lorente MA, Dupuis V. Compomers: between glass-ionomer cements and composites. Biomaterials. 1998;19(6):529-39.

6. Wilson AD. A new translucent cement for dentistry: the glass-ionomer cement. $\mathrm{Br}$ Dent J. 1972;132:133-5.

7. Diaz-Arnold AM, Vargas MA, Haselton DR. Current status of luting agents for fixed prosthodontics. J Prosthet Dent. 1999;81(2):135-41.

8. Yiu CK, Tay FR, King NM, Pashley DH, Carvalho RM, Carrilho MR. Interaction of resin-modified glass-ionomer cements with moist dentine. J Dent.2004; $1 ; 32(7): 521-30$.

9. Bagheri R. Film thickness and flow properties of resin-based cements at different temperatures. J Dent. 2013;14(2):57.

10. Rosenstiel SF, Land MF, Crispin BJ. Dental luting agents: A review of the current literature. J Prosthet Dent. 1998;80(3):280-301.

11. DENTISTRY-WATER-BASED CEMENTS PART, I. S. O. Powder/liquid acid-base cements. ISO, 1, 9917-1.

12. Data sheets from GC Fuji 1 according to $1907 / 2006 /$ EC, Article 31,version 2

13. White SN, Yu Z. Film thickness of new adhesive luting agents.J Prosthet Dent. 1992;67(6):782-5.

14. Johnson GH, Herbert AH, Powers JM. Changes in properties of glass-ionomer luting cements with time. Oper Dent. 1988;13(4):191-6.

15. Kyrios DM, Duke ES, Windeler AS. Glass-ionomer cement film thickness and working time. J Prosthet Dent. 1989;62(5):533-6.

16. Sidhu S, Nicholson J. A review of glass-ionomer cements for clinical dentistry. J Funct Biomater. 2016;7(3):16.

17. Sakaguchi RL, Powers JM. Craig's restorative dental materials-e-book. Elsevier Health Sciences; 2012.

18. Zahra VN, Kohen SG, Macchi RL. Powder-liquid ratio and properties of two restorative glass ionomer cements. Acta Odol Latinoam. 2011;24(2):200-4.

19. Fan M, Wang F, Wang C. Reflux Precipitation Polymerization: A New Platform for the Preparation of Uniform Polymeric Nanogels for Biomedical Applications. Macromol Biosci. 2018;18(8):1800077.

20. Based cements-Part DW. 1: Powder/liquid acid-base cements. ISO/FDIS. 2007;10:9917-1

21. Fleming GJ, Farooq AA, Barralet JE. Influence of powder/liquid mixing ratio on the performance of a restorative glass-ionomer dental cement. Biomaterials. 2003;24(23):4173-9.

22. De Souza Balbinot G, Garcia IM, Samuel SM, Collares FM, Leitune VC. Influence of Octacalcium Phosphate addition on physical-mechanical properties of Glass Ionomer Cement. Revista Odonto Ciência. 2017;32(3):127-30.

23. De Caluwé T, Vercruysse CW, Fraeyman S, Verbeeck RM. The influence of particle size and fluorine content of aluminosilicate glass on the glass ionomer cement properties. Dent Mat. 2014;30(9):1029-38. 